\title{
Experimental Investigation of Mechanical and Physical Properties of Short Flax Fibres Pulp Reinforced Composites Material Sheet
}

\author{
Anupam Kumar ${ }^{1}$, Ramratan $^{2 *}$ and Rohit Kumar ${ }^{3}$ \\ ${ }^{1}$ Professor, Department of Textile Engineering, Giani Zail Singh Campus College of Engineering and Technology, Maharaja Ranjit Singh \\ Punjab Technical University, India
}

${ }^{2}$ Assistant Professor, Department of Textile Engineering, Giani Zail Singh Campus College of Engineering and Technology, Maharaja Ranjit Singh Punjab Technical University, India

${ }^{3}$ Research Scholar Department of Textile Engineering, Giani Zail Singh Campus College of Engineering and Technology, Maharaja Ranjit Singh Punjab Technical University, India

*Corresponding author: Ramratan, Assistant Professor, Department of Textile Engineering, Giani Zail Singh Campus College of Engineering and Technology, Maharaja Ranjit Singh Punjab Technical University, Bathinda-151001, Punjab, India

\begin{abstract}
In this experiment short flax fiber pulp is the natural fiber component chemically treated with alkaline solutions. Six specimens will be prepared in different volume percentage of flax fiber pulp and epoxy resin in order to get more accurate results. In this study it has been aimed to use flax fibres in composite materials and to study the mechanical properties of the produced samples. The mechanical tests results (thickness test, Tensile strength and impact strength tests) and SEM micrographs indicated flax fibres as an alternative natural fibre source for developing reinforced composites for various industries. The content of short flax fiber pulp is varied $(35 \%, 45 \%, 55 \%)$ weight percentage whereas the epoxy resin is varied $(50 \%, 40 \%, 30 \%)$ percentage is kept constant $15 \%$ in hardener. Composites have been fabricated using hand layup technique using a suitable mold developed in industry. All the sample have been tested in universal testing machine as per ASTM standard for tensile strength and impact strength it is observed that composite with 35\% flax fiber pulp is having highest tensile strength of $4 \mathrm{~mm}$ (4.34 Mpa) and $8 \mathrm{~mm}$ (6.02 Mpa). The impact strength of composite with $35 \%$ flax fiber pulp was highest than $45 \%$ to $55 \%$ flax fiber pulp.
\end{abstract}

Keyword: Flax fiber pulp; Tensile strength; Impact strength

\section{Introduction}

Nowadays, scientists and engineering working in the field of material are too concerned with sustainability issues and environmental protection. Therefore, environmentally friendly, natural, recycled, or biodegradable material are attracting lot of interest $[1,2]$. Due to environmentally friendly, bio degradation and sustainability, natural fiber composites are preferred as compared to conventional synthetic fiber-based composite. Composites material are those materials which built from two or more constituent material with considerably different physical or chemical properties that when joined to develop composite $[3,4]$. Composite material depends on the properties of constituent material the fiber and the resin used. At present day, the advance composites material has been broadly used composite in the engineering field due to their noble mechanical properties. Advantages of this like as corrosion resistance, electrical insulation, more stiffness and strength, fatigue resistance lesser in weight than metal, easy process ability at less energy requirements in tooling and assembly costs widely acceptable in structure Application $[5,6]$. A lot of advanced research literature is mentioned on natural fiber reinforced green composites in the way of refining mechanical strength and mark them suitable in many engineering applications. The composite prepared from thermosetting resin which cannot be reproduce or recycle. Because of these aims the attention of composite material going in the direction of the green composites. Which do not have a negative effect on the environment and they are biodegradable, full sustainable, environment friendly in nature. 
All the above reasons force the researches to develop material that are biodegradable in nature and have good mechanical properties $[7,8]$. This research paper aims to discuss the development of different form of flax fiber pulp rein forced polymer composites and their mechanical characterization and their mechanical characterization as per ASTM standard. natural fiber is composed of cellulose, hemicelluloses and lignin and pectin. This resulted in the important problem of compatibility between fiber and matrix due to weakness in the adhesion between to surface fiber and the polymer matrix so changing the fiber surface by treatment. It is the best method that researchers use to improve the strength and the compatibility between the interfacial bond strength $[9,10]$.

The surface treated fibers showed better efficiency then the untreated. This sodium hydroxide treatment removes hemicelluloses and lignin hiding the surface of the fiber. It is accepted that the sodium hydroxide treatment result from increases surface roughness which create better mechanical interlocking between fiber pulp. This research paper aims to discuss the development of different form of flax fiber pulp reinforced polymer composites and their mechanical characterization as per ASTM standard [11-13]. The developed sisal fibre and its composites. The properties of sisal fibre itself interface between sisal fibre and matrix, properties of sisal-fibre in forced composites and their hybrid composites have been reviewed. It is observed Sisal and glass fibres can be combined to produce hybrid composites which take full advantage of the best properties of the constituents. Almost all the mechanical properties show 'positive' hybrid effects [14]. The highlighted that natural fibers are suitable for load bearing materials such as roofs and beams. If the materials have tensile strength more than 50Mpa they can be used in roofs. Furthermore, for infrastructure applications where the use of synthetic fibers is not suitable, natural fibers can be a suitable substitute. Jute mats reinforced composites have been used for trenchless rehabilitation of underground drainpipes and water pipes. Availability of fibers is also an important parameter for mass production [15]. Mechanical properties of woven jute fabric reinforced poly (L-lactic acid) composites. Woven jute composites in warp and weft directions presented superior mechanical properties than non-woven jute fabric (NWJF) composites. The influence of woven structure and direction on the properties such as tensile, flexural and impact properties was investigated. Finally, it can be concluded that PLLA based woven jute fabric composites might be a good alternate of synthetic fiber composites and are suitable for high load bearing applications [16]. The investigation on bidirectional jute fiber, a natural fiber abundantly available in India. The minimum and maximum void content are in neat epoxy and $12 \mathrm{wt}$ \% fiber loading specimens respectively. It is also found from the study that the void content decreases with the increase in fiber loading. The hardness, tensile properties and impact strength of the jute-epoxy composites increases with the increase in fiber loading. Flexural strength and inter-laminar shear strength are greatly influenced by the void content [17]. Tabulated the values of different plant fibers and compared it with glass fibers. The tensile strength and the young's modulus of the synthetic fibers are visibly much higher than that of the natural fibers. However, the difference in the specific values of synthetic and natural fiber, most important with respect to applications, is not as great. Jute and flax have similar and better mechanical properties compared to other natural fibers. Further the jute fibers are less dense than flax [18]. It has surveyed the use of natural fibers in automotive sectors and have found that demand is increasing day by day. We can also see the importance of compression molded parts. Major automotive suppliers make the most substantial contribution to the use of natural fibers for composites. For the future, one can expect other models in other vehicle segments and means of transport (e.g. small cars, trucks, trains), as well as in other European countries, to be fitted with natural fiber press-molded parts [19].

The aim of this study is utilized agricultural waste which may be profitable, pollution free and economically viable for the farmer and industries. These composites are also used in panel for partition and false ceiling, wall sheet, floor, window and door frame. This present research works a short flax fibres pulp reinforced epoxy composite material sheet has been utilized with 35\%, 45\%, 55\%. but previous literature view studies according to was utilized flax fibre composite sheet $15 \%$ to $25 \%$. Application of high-performance composites using natural fibers is increasing in various engineering field. Composite material comprising one or more phase belonging to natural or biological origin. The composites produced today with the incorporation of natural fiber as reinforcements. In epoxy matrix are used for boat hulls, surfboards, sporting goods, building panel this not only reduces the cost but also save from environmental pollution.

\section{Materials and Methods}

\section{Materials}

Raw Materials: Short flax fiber put $1 \mathrm{~kg}$ fiber in the cooking pot. Make a solution of sodium hydroxide pour the solution in the pot with flax fiber and boil for 2 to 3 hour, after that, it will become pulp and we will wait for it to cool down and wash him with water three to four time, after that we will blend with the help of blending machine and then we will are squeeze with help of cotton fabric.

Reinforcement: The purpose of the reinforcement in a composite material is to increase the mechanical properties of the neat resin system. All of the different fibers used in composites have different properties and so affect the properties of the composite in different ways. For most of the applications, the fibers need to be arranged into some form of sheet, known as a fabric, to make handling Possible.

Natural fiber composites: Natural fiber composites are made of cotton, flax, jute, sisal, hemp and non-conventional fiber such as coir \& different EFBs (empty fruit bunches) and wood fibers. Wood fiber thermoplastic composites are attractive, insect- and rot- 
resistant, and paintable that can be made to have the look of wood. In addition, they are stiffer, cheaper than plastic products, with more life cycle coseo, vegetable fiber thermoplastic composites are attractive to the automotive industry because of their low density and ecological advantages over conventional composites natural fibres are lingo cellulosic in nature. These composites are gaining importance due to their non-carcinogenic and bio-degradable nature. The natural fiber composites can be very cost-effective material especially for building and construction industry (panels, false ceilings, boards etc.) packaging, automobile and railway coach interiors and storage devices. This also can be a potential candidate in making of composites, especially for partial replacement of high

Table 1: Chemical composition of flex fiber. cost glass fibers for low load bearing applications.

Preparation of composites sheet: After that, the polyester resin and hardener mixed in a container and stirred well for 3 to 5 minutes. The flax fiber pulp was then added gradually and Stirred to allow proper dispersion of fiber pulp within the gel like mixture. Before the mixture were poured inside the mould, the mould was initially polished with a release agent to prevent the composites from sticking to the mould upon removal. Finally, after the mixture had been poured into the mould, it was left at sunlight for 3 to 5 day. For fully cured and hardened.

Hardener: To convert epoxy resin to epoxy plastic a reaction take place with a suitable substance called hardener. Tables $1 \& 2$.

\begin{tabular}{|c|c|c|}
\hline S.no & Properties (\%) & Range \% \\
\hline 1 & Cellulose & 56.5 \\
\hline 2 & Hemi-cellulose & 2.5 \\
\hline 3 & Lignin & 3.4 \\
\hline 4 & Pectin & 1.3 \\
\hline 5 & Fat \& wax & 10.5 \\
\hline 6 & Water soluble materials & \\
\hline
\end{tabular}

Table 2: Sample composition.

\begin{tabular}{|c|c|c|c|c|}
\hline S. No. & Thickness $(\mathbf{m m})$ & Pulp ratio $\%$ & Epoxy $\%$ & Hardener $\%$ \\
\hline 1 & 4 & 35 & 50 & 15 \\
\hline 2 & 4 & 45 & 40 & 15 \\
\hline 3 & 4 & 55 & 30 & 15 \\
\hline 4 & 8 & 35 & 50 & 15 \\
\hline 5 & 8 & 45 & 40 & 15 \\
\hline 6 & 8 & 55 & 30 & \\
\hline
\end{tabular}

Reason to choose flax fiber pulp: Short flax fiber is most widely use flax fiber pulp reinforced biodegradable polymer are the category of the composites in which flax fiber pulp is used as reinforcements. There are lot of biodegradable polymer are available as polylactic acid (PLA), poly hydroxyl - butyrate (PHB). A lot of research work has been done with the help of all these is a wide scope of research is there in future specially on the machining of these biodegradable polymer composites. Flax fiber pulp superior on light weight and environmentally friendly. After completing of usable life of product made up from green composite. It can be completely dissolved after buried in the soil and residual left as carbon dioxide and water. Green composites are a renewable, environmentally friendly and biodegradable in nature.

\section{Methods}

Thickness testing: For measuring the Thickness of a wire or a plate, calipers micrometer is used. Principal of the measurement of sheet thickness, the sample is kept between two plane parallel plate and a known arbitrary pressure is applied between the plates than the distance between the plate is measured precisely. The thickness test was performed as per ASTMD - 1777 standard.

Tensile strength testing: Tensile strength is the ability of material to Resist the forces that pulls it apart or it is the resistance of material to breakage under tension. The tensile test was performed as per ASTMD - 638 standards. For tensile testing the Specimen were cut as per the dimensions, detailed dimensions for this are shown in figure the test were conducted using a universal testing machine (UTM). Two sample of each composite were tested, and their mean value are taken. (Figures 1-3)

Tensile strength $=$ maximum load $/$ Area of Specimen

Impact strength: Impact strength is the ability of a material to absorb impact energy without breaking. Impact test are performed to know the toughness of material. The specimen was subjected to a large amount of force for a small interval of time. A material with more impact energy will have more toughness. For impact strength testing the Specimen were cut as per the dimensions, detailed dimensions for this are shown in (Figures 4-6). 


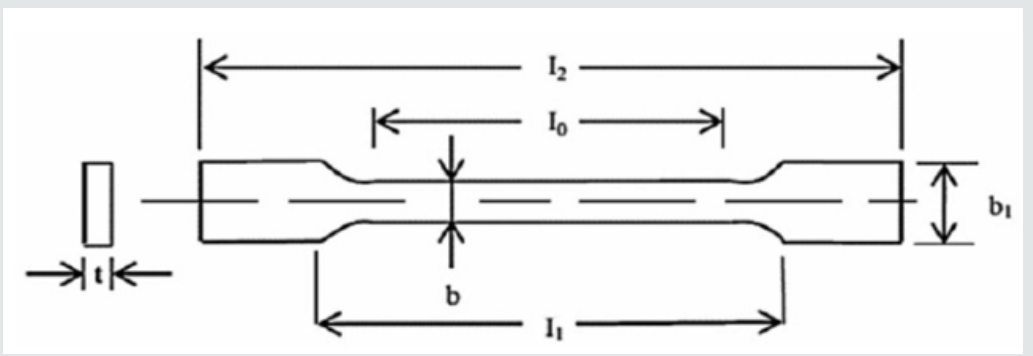

Figure 1: Tensile specimen dimensions shape.
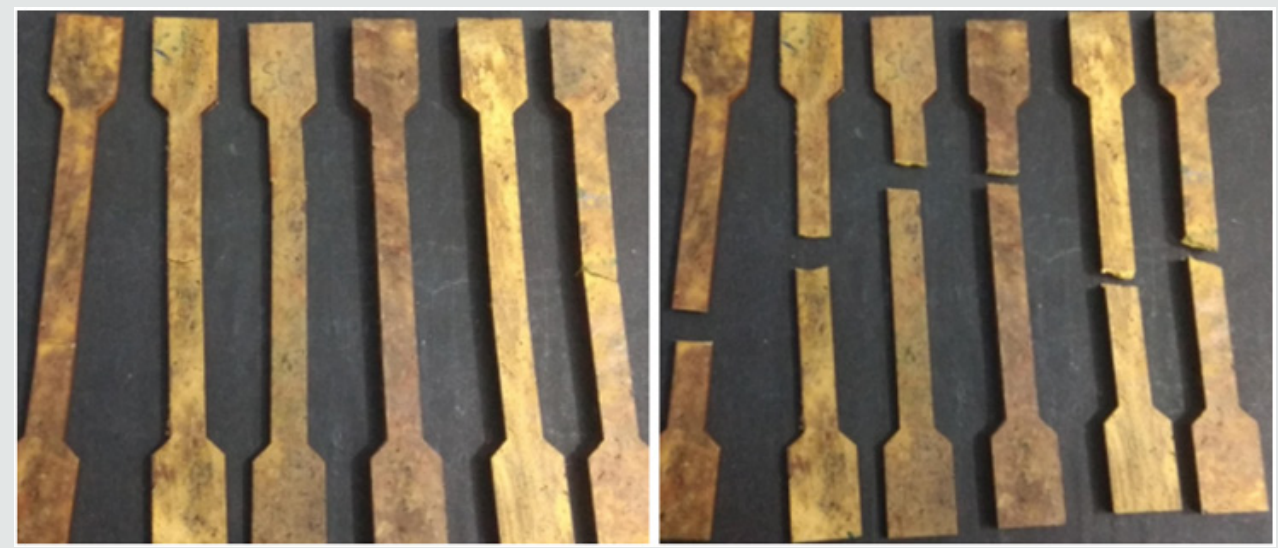

Figure 2: (a) tensile strength specimen, (b) After tensile strength testing.

Figure 3: Tensile strength instruments.
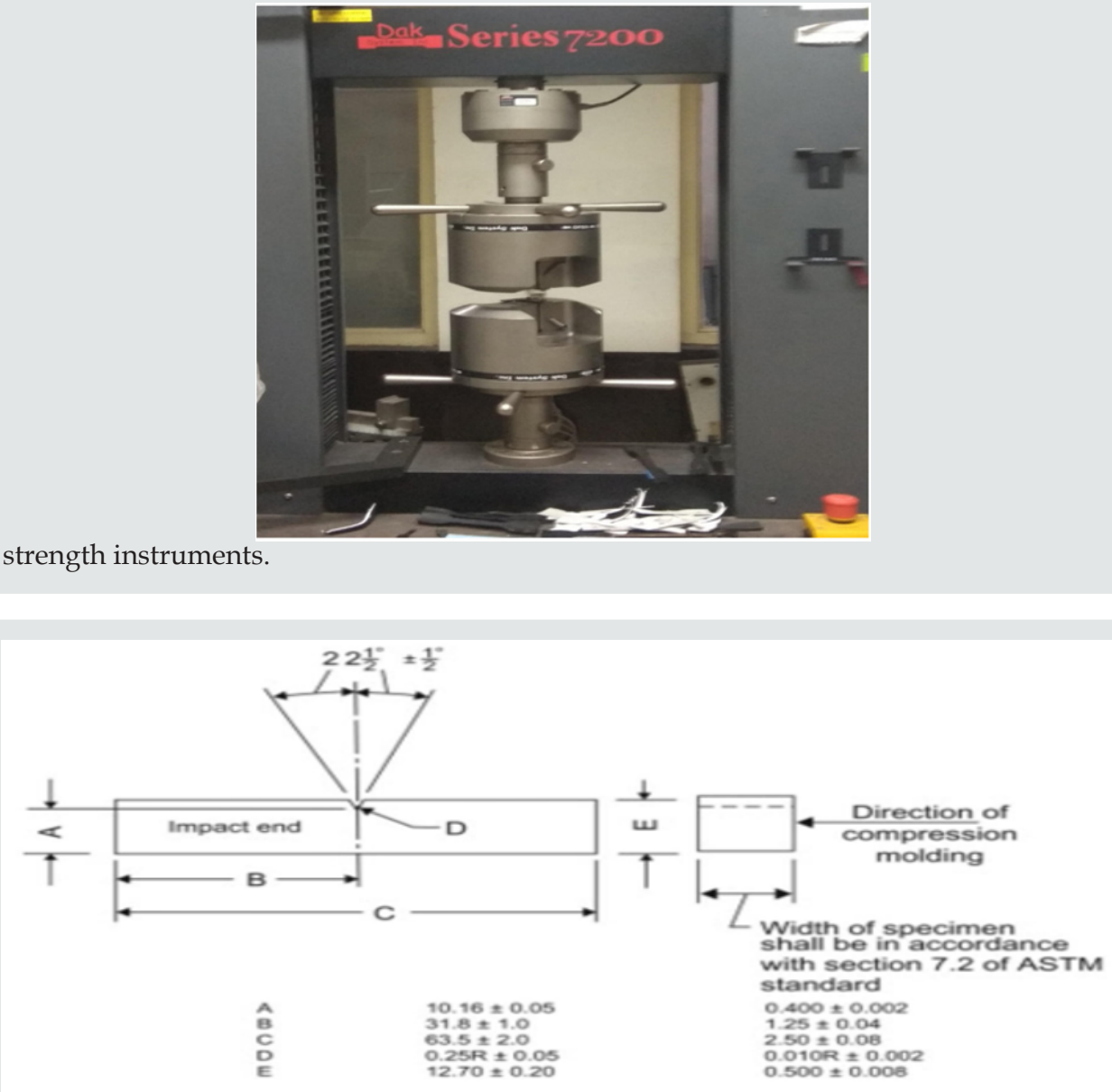

Figure 4: Impact strength instrument. 


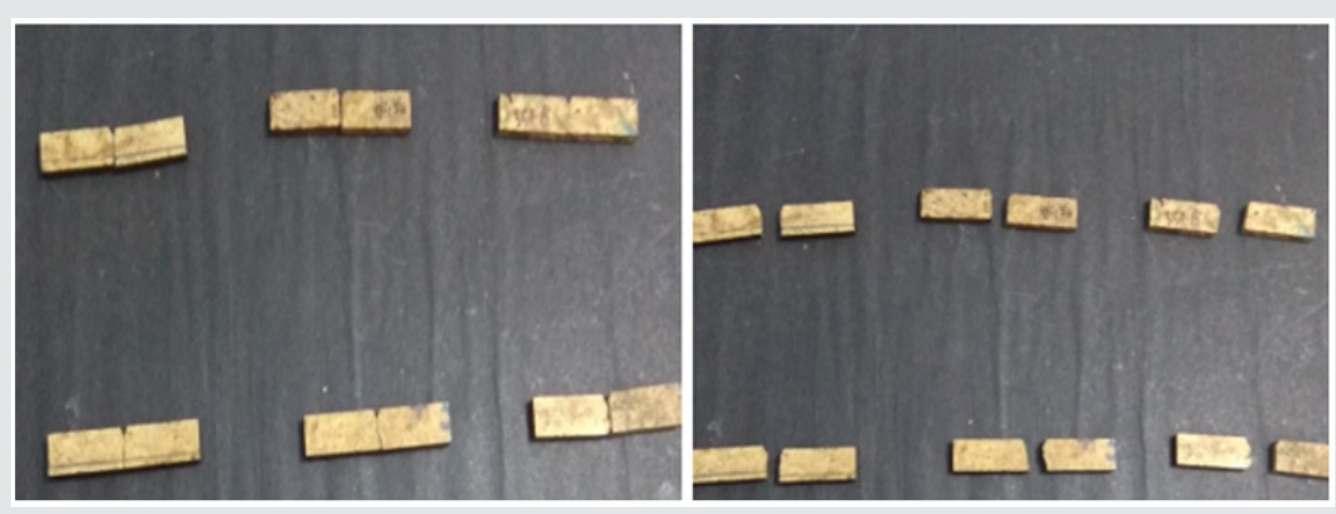

Figure 5: (a) Impact specimen, (b) after impact strength.
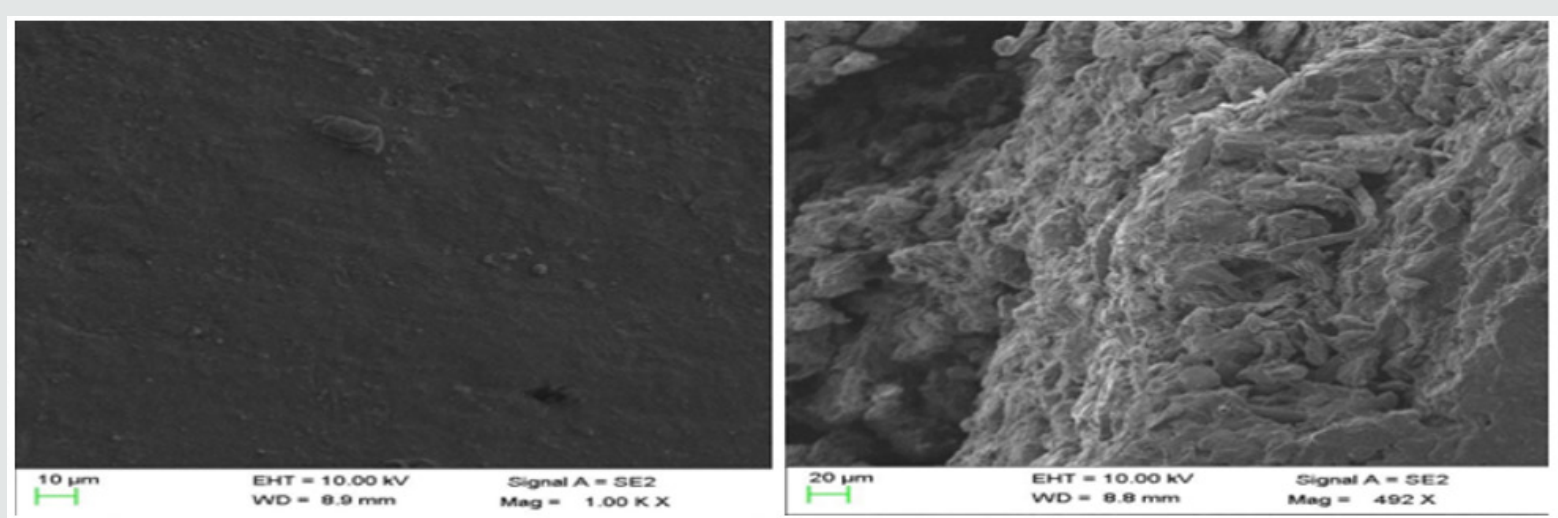

Figure 6: (a) Different beam light penetration of the SEM images for Composite.

Fractured surface morphology using field Emission scanning Electron microscope (FESEM)

SEM is basically an electron microscope that images the sample surface by scanning it with a high. Energy beam of electrons. The signals produced by SEM result from interaction of the electron
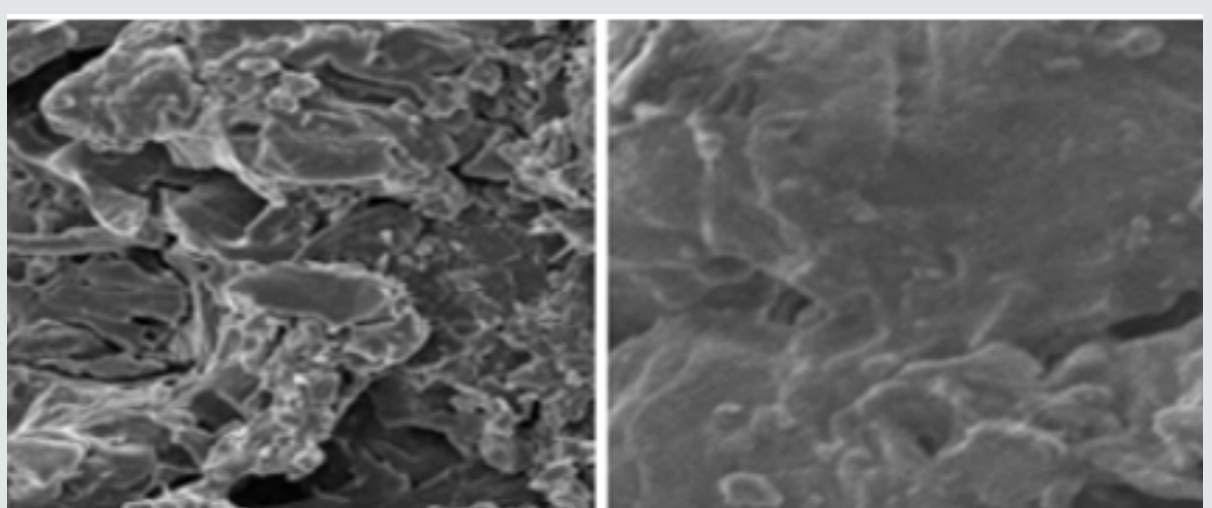

Figure 7: (b) Different beam light penetration of the SEM images for Composite sheet. beam with atom at or near the surface of the sample SEM can produce very high-resolution images of a sample surface Revealing details about less than 1 to 5 min in size due to the very Narrow electron beam. SEM micrographs have a large depth of field yielding a characteristic three-dimensional Appearance useful for understanding the surface of a sample show below (Figure 7a \& b). 


\section{Results and Discussions}

Tables 3-10.

Table 3: Sheet thickness test.

\begin{tabular}{|c|c|c|c|}
\hline S.no & Pulp ratio (\%) & Various thickness (mm) & Mean thickness(mm) \\
\hline 1 & 35 & $4.23,4.56,4.37,4.46,4.76,4.40,4.52,4.38,3.95,4.02$ & 4.365 \\
\hline 2 & 45 & $4.44,4.25,4.45,4.35,4.65,4.75,4.98,5.07,5.17,5.12$ & 4.723 \\
\hline 3 & 55 & $4.02,4.12,4.23,4.39,4.27,4.52,4.56,4.75,4.37,4.44$ & 4.372 \\
\hline 4 & 35 & $8.12,8.25,8.45,8.52,8.75,8.42,8.35,8.21,8.42,8.72$ & 8.421 \\
\hline 5 & 45 & $8.21,8.23,8.24,8.44,8.12,8.62,8.36,8.54,8.41,8.75$ & 8.392 \\
\hline 6 & 55 & $8.35,8.46,8.65,8.37,8.56,8.28,8.14,8.19,8.23,8.40$ & 8.363 \\
\hline
\end{tabular}

Table 4: Sample GSM.

\begin{tabular}{|c|c|c|c|c|}
\hline S. No & Thickness $(\mathbf{m m})$ & Pulp ratio $\mathbf{~}$ & Weight $\mathbf{( g m )}$ & GSM $\left(\mathbf{g} / \mathbf{m}^{\mathbf{2}}\right)$ \\
\hline 1 & 4 & 35 & 153 & $153 \mathrm{gm} / 0.03=5100$ \\
\hline 2 & 4 & 45 & 138 & $138 \mathrm{gm} / 0.03=4600$ \\
\hline 3 & 4 & 55 & 126 & $126 \mathrm{gm} / 0.03=4200$ \\
\hline 4 & 8 & 35 & 243 & $243 \mathrm{gm} / 0.03=8100$ \\
\hline 5 & 8 & 45 & 232 & $232 \mathrm{gm} / 0.03=7733$ \\
\hline 6 & 8 & 55 & 222 & $222 \mathrm{gm} / 0.03=7400$ \\
\hline
\end{tabular}

Table 5: Sample density.

\begin{tabular}{|c|c|c|c|}
\hline S.no & Thickness(mm) & Pulp Ratio $\%$ & Density $\left(\mathrm{g} / \mathbf{m}^{3}\right)$ \\
\hline 1 & 4 & 35 & $153 \mathrm{gm} / 120=1.275$ \\
\hline 2 & 4 & 45 & $138 \mathrm{gm} / 120=1.150$ \\
\hline 3 & 4 & 55 & $126 \mathrm{gm} / 120=1.050$ \\
\hline 4 & 8 & 35 & $243 \mathrm{gm} / 240=1.012$ \\
\hline 6 & 8 & 45 & $232 \mathrm{gm} / 240=0.966$ \\
\hline
\end{tabular}

Table 6: Tensile specimen dimension size.

\begin{tabular}{|c|c|c|c|}
\hline S.no. & Symbol & Description & Dimension(mm) \\
\hline 1 & I0 & Gauge length & 145 \\
\hline 2 & I1 & Grip distance & 240 \\
\hline 3 & I2 & Wverall length & 160 \\
\hline 4 & B & Width end & 30 \\
\hline 6 & b1 & Thickness & 4,8 \\
\hline
\end{tabular}

Table 7: Impact specimen dimensions.

\begin{tabular}{|c|c|c|}
\hline S. No & Description & Dimension (mm) \\
\hline 1 & Length of specimen & 2.54 \\
\hline 2 & Centering of notch & 0.25 \\
\hline 3 & Radius of notch type V & $45^{\circ}$ \\
\hline 4 & Angle of notch & 12.7 \\
\hline 5 & Width & 4,8 \\
\hline 6 & Thickness & \\
\hline
\end{tabular}


Table 8: Impact Specimen dimension.

\begin{tabular}{|c|c|c|}
\hline S.no & Description & Dimension(mm) \\
\hline 1 & Length of Specimen & $63.5 \mathrm{~mm}$ \\
\hline 2 & Centering of notch & $2.54 \mathrm{~mm}$ \\
\hline 3 & Radius of notch type V & $0.25 \mathrm{~mm}$ \\
\hline 4 & Angle of notch & $45^{\circ}$ \\
\hline 5 & Width & 12.7 \\
\hline 6 & Thickness & 4,8 \\
\hline
\end{tabular}

Table 9: Tensile strength results.

\begin{tabular}{|c|c|c|c|c|c|}
\hline S. No & Pulp ratio (\%) & Thickness (mm) & $\begin{array}{c}\text { Tensile strength } \\
\text { 1(Mpa) ASTMD 638 }\end{array}$ & $\begin{array}{c}\text { Tensile strength 2 } \\
\text { (Mpa) ASTMD 638 }\end{array}$ & Mean tensile strength \\
\hline 1 & 35 & 4 & 4.72 & 3.96 & 4.34 \\
\hline 2 & 45 & 4 & 3.86 & 3.44 & 3.65 \\
\hline 3 & 55 & 4 & 2.56 & 2.92 & 2.74 \\
\hline 4 & 35 & 8 & 7.35 & 4.69 & 6.02 \\
\hline 5 & 45 & 8 & 5.12 & 4.21 & 4.66 \\
\hline 6 & 55 & 8 & 3.46 & 3.23 & 3.34 \\
\hline
\end{tabular}

Table 10: Impact strength results.

\begin{tabular}{|c|c|c|c|c|c|}
\hline S. No & Pulp ratio (\%) & Thickness (mm) & $\begin{array}{c}\text { Impact energy 1(Kj/ } \\
\mathbf{m}^{2} \text { ) ASTMD 256 }\end{array}$ & $\begin{array}{c}\text { Impact Energy 2(Kj/ } \\
\mathbf{m}^{2} \text { ) ASTMD 256 }\end{array}$ & \begin{tabular}{c} 
Mean Impact energy \\
\hline 1
\end{tabular} \\
\hline 35 & 45 & 1.76 & 1.21 & 1.485 \\
\hline 3 & 55 & 4 & 1.16 & 1.27 & 1.215 \\
\hline 4 & 35 & 4 & 1.46 & 1.37 & 1.415 \\
\hline 5 & 45 & 8 & 3.12 & 2.59 & 2.855 \\
\hline 6 & 55 & 8 & 2.13 & 1.26 & 1.695 \\
\hline
\end{tabular}

\section{Density for the Composite Sheet}

a. The density testing was done on six composite plate and the result are noted in form of Table 5 .

b. As we can see that as pulp to resin ratio, when the percentage of pulp is decrease, we have increase in density of composites. c. But as the density increases results in increases of hardness of sheet as measured above.

d. As per shows (Figure 8) analysis of composite plate of Density module of composites.

e. The decrease in pulp percentage give higher density as analyzed by the graph.

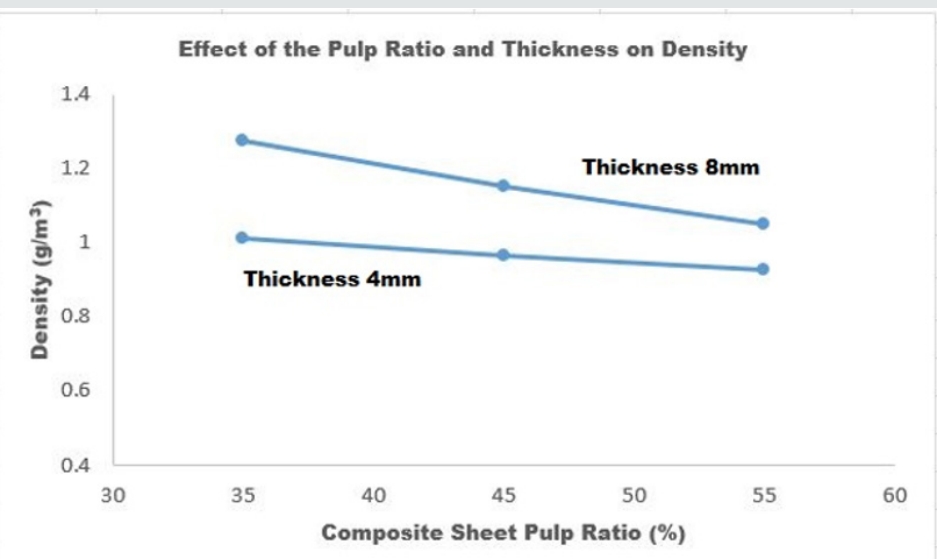

Figure 8: Pulp ratio and density of the composites sheet. 


\section{Tensile Strength for the Composite Sheet}

Six different types of composites sample are tested In DAK series 7200 machine name universal testing machine. Sample are lifted to break till the ultimate strength occurs. The Table 9 the variation in tensile strength of different samples. a. The tensile testing was done on six composite sheet and result are noted in form of Table 9.

b. As per show the below (Figure 9). It clearly Analyze the data which lead to highest tensile strength of composite sheet having composition of 35\%pulp and 50\% Resin.

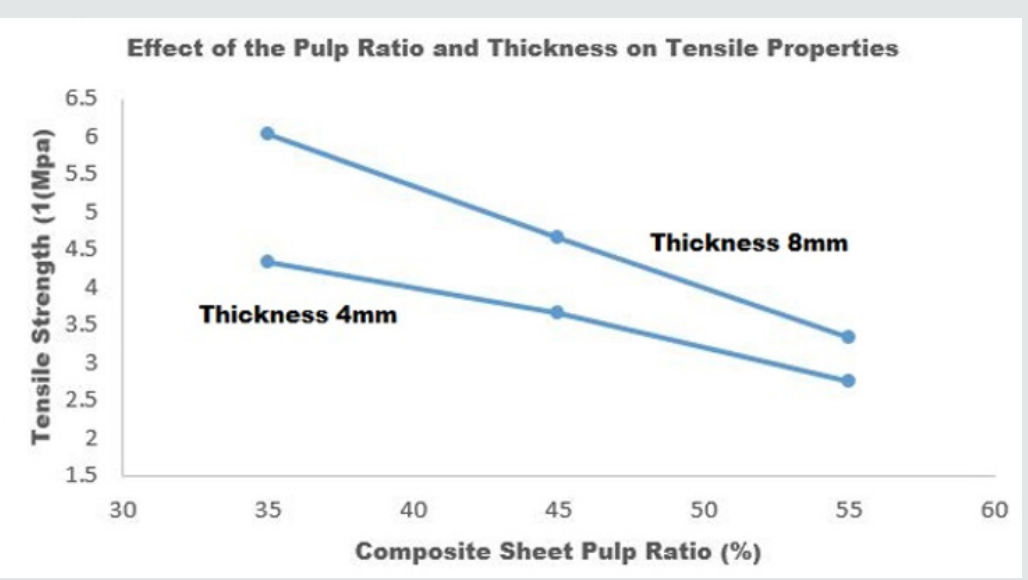

Figure 9: Pulp ratio and mean tensile strength of the composites sheet.

\section{Impact Strength for the Composite Sheet}

The impact capability of sample impact test is carried out using Izod-charpy digital impact testing machine. Absorbed energy obtained for six different composite sample from the machine. The Table 10. Shows the variation in impact strength of different samples. a. The impact testing was done on six composite sheet and result are noted in form of Table 10.

b. The graph shows analysis of composite sheet of impact strength

c. The below (Figure 10). It clearly Analyze the data which lead to highest impact strength of composite sheet having composition of $35 \%$ pulp and $50 \%$ resin.

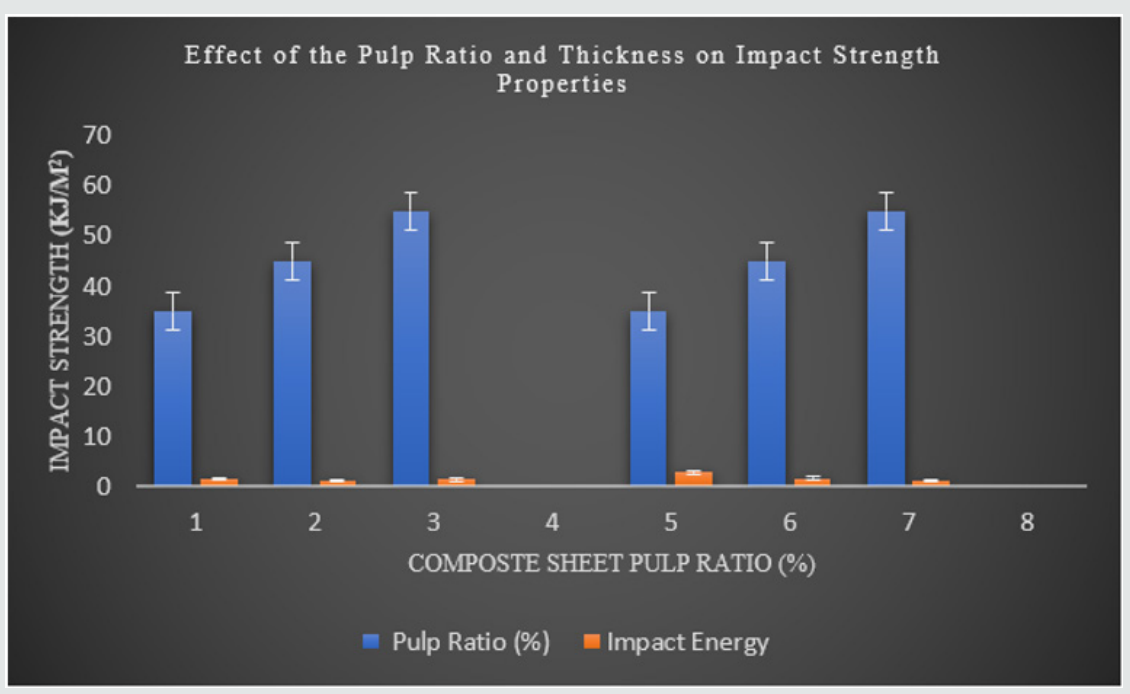

Figure 10: Pulp ratio and mean impact energy of the composites sheet.

\section{Conclusion}

The results of the work show that a useful composite with good properties could be successfully development using wheat straw pulp as reinforcing agent for the Polymer of composites tensile strength and impact strength. This process leads to finding the optimum composition and methodology to manufacture such a composite material. This study involves mechanical Characterization of properties of Wheat straw pulp epoxy resin composites. experimental and analytical observation of pulp or resin composites leads to following. 
a. The decrease in pulp percentage give higher density of composites sheet.

b. As we can see that as pulp to resin ratio, when the percentage of pulp is increasing, we have decrease in tensile strength.

c. The decrease in pulp percentage give higher impact strength of composite sheet.

d. The aim of this study is utilized agricultural waste which may be profitable, pollution free and economically viable for the farmer and industries.

e. These composites are also used in panel for partition and false ceiling, wall sheet, floor, window and door frame.

\section{Acknowledgement}

The Authors wishes to express their heartfelt gratitude to the authorities of GZSCCET Bathinda to provide the facilities for conducting the Required test in their laboratories. Special thanks are also due to HOD and staff of textile Engineering Department of Giani Zail Singh campus college of engineering and technology, without whose help this work would not have been completed.

\section{References}

1. Nattakan Soykeabkaew, Pitt Supaphol, Ratana Rujiravanit OPreparation and characterization of Jute- and flax-reinforced starch-based composite foams. Polymer processing and polymer nanomaterials research unit, academia.edu, Thailand

2. Thiruchitrambalam M, Alavudeen A, Athijayamani A, Venkateshwaran, Elaya A P (2009) Improving mechanical properties of banana/kenaf polyester hybrid composites using sodium laulryl sulfate treatment. Materials Physics and Mechanics 9(2): 165-173.

3. Naira KCM (2000) Rheological behavior of short sisal fiber-reinforced polystyrene composites. Composites: Part A 31(2): 1231-1240.

4. M. Ramesh, et al. (2013) Mechanical property evaluation of sisal-juteglass fiber reinforced polyester composites. Composites: Part B 48(1): $1-9$.

5. Arun Kumar Rout, Alok Satapathy (2012) Study on mechanical and tribo - performance of rice -husk filled glass-epoxy hybrid composites. Materials and design 41(2): 131-141.

6. Haameem MJA, Abdul Majid MS, Afendi M, Marzuki HFA, Fahmi I et al. (2016) Mechanical properties of napier grass fibre/polyester composites. Composite structures 136(2): 1-10.
7. Nasmi Herlina sari, I. N. G. Wardana, Yudy Surya Irawan, Eko S. Physical and acoustical properties of corn husk fiber panels. Advances in acoustics and vibration, 2016, 2(1), 1- 8.

8. Henry Obasi C (2015) Peanut husk filled polyethylene composites: effects of filler content and compatibilizer on properties. Hindawi publishing corporation. Journal of polymers.

9. Akshay Baria N, Sagar Choksi (2016) Wear and friction behaviour of corn husk fiber reinforced polyester composites. International journal for scientific research \& development 4(5): 803-806.

10. Sudeep Deshpande TR (2014) Effect of Fillers on E-Glass/Jute Fiber Reinforced Epoxy Composites" Int. Journal of Engineering Research and Applications 4(8): 118-123.

11. Sandhyarani Biswas, Alok Satapathy and Amar Patnaik (2010) Effect of ceramic fillers on mechanical properties of bamboo fiber reinforced epoxy composites a comparative study. Advanced Materials Research 123(125): 1031-1034

12. Akindapo Jacob Olaitan, Emmanuel Terhemen AGOV, Danladi King G, Rapheal Oluwatoyin O (2017) Comparative assessment of mechanical properties of groundnut shell and rice husk reinforced epoxy composites. American journal of mechanical engineering 5(3): 76-86.

13. Selakumar K, Omkumar M (2017) Characterization of human hair fiber reinforced polymer composites. Proceedings of an international conference on recent trends in nature production engineering, MIT, Anna University 2(1): 83-84.

14. Yan Li, You Wing Mai, Lin Ye (2000) Sisal fibre and its composites: a review of recent developments" Composites Science and Technology 60(1): 2037-2055.

15. Kandachar P, Brouwer R (2002) Applications of bio-composites in industrial products. Mater Res Soc Symp Proc 702(2): 101-112.

16. Anon (2002) The competitiveness of natural fibers-based composites in the automotive sector the Sisal Agribusiness in Brazil. Mater Res Soc Symp Proc 702(1): 113-139.

17. Santulli C (2001) Post-impact damage characterization on natural fiber reinforced composites using acoustic emission. NDT\&E International 34(8): 531-536.

18. Andrzej Bledzkia K, Wenyang Zhang, Andris Chateb (2001) Naturalfibre-reinforced polyurethane micro foams. Composites science and technology 61(2): 2405-2411.

19. Senthil Kumar K, Siva I, Jeyaraj P, Winowlin Jappes JT, Amico SC et al. (2014) Synergy of fiber length and content on free vibration and damping behavior of natural fiber reinforced polyester composite beams. Materials and design 56(1): 379-386.
This work is licensed under Creative Commons Attribution 4.0 License

To Submit Your Article Click Here: Submit Article
DOI: 10.32474/MAMS.2020.02.000149

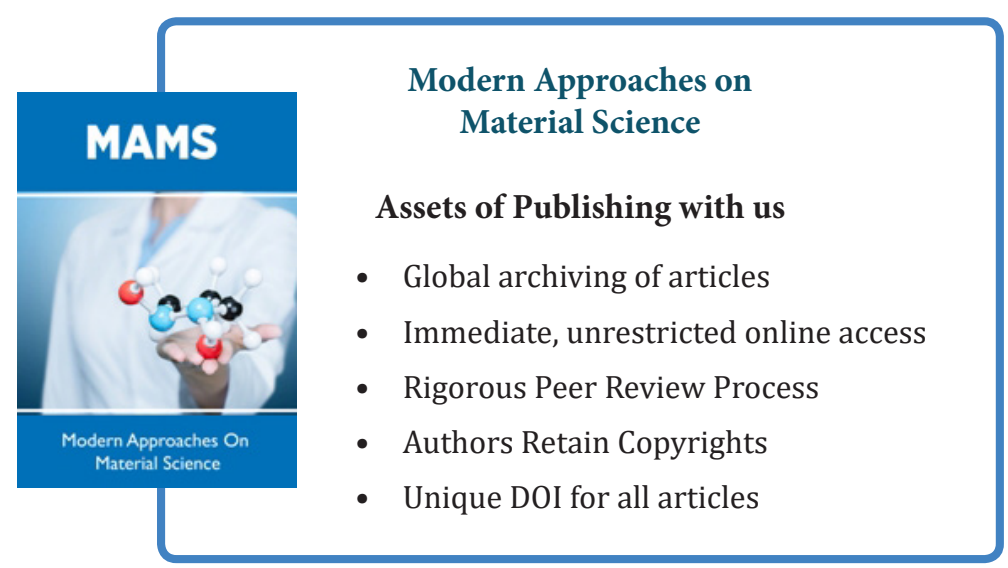

